\title{
Rancang Bangun Robot Line Follower Portable Sebagai Upaya Minimalisasi Sampah Elektronik di Ranah Robotika
}

\author{
Nova Eka Budiyanta ${ }^{1}$, Harlianto Tanudjaja ${ }^{1}$, Melisa Mulyadi ${ }^{1}$
}

\begin{abstract}
The accumulation of electronic waste is starting to be in the spotlight throughout the world. Apart from these problems robotics activities are increasingly developing throughout the world. Many robotics competitions are held as a forum for the creativity of a community so that inevitably the use of electronic components is increasing. The use of electronic components can be a trigger for the accumulation of electronic waste. This cannot be avoided because in the process of developing the robot it is possible for the electronic modules that be used in the experiment are have some problems so they have to replaced with new electronic modules. To minimize the accumulation of electronic waste can be done by making a portable electronic module so that several components can be installed and removed easily. Portability of a good electronic module can minimize component replacement if there is damage to the module. In this study discussed about the design of Robot Line Follower which can be assembled in a portable manner in which there are several modules that can be easily installed and removed. The sensor used in this robot is a photodiode, involving the Arduino Nano controller as a control center, L298N motor driver as a motor driver, and a $12 \mathrm{~V} \mathrm{DC} \mathrm{motor} \mathrm{as} \mathrm{an} \mathrm{actuator.} \mathrm{Not} \mathrm{forgetting} \mathrm{also} \mathrm{the} \mathrm{robot} \mathrm{body} \mathrm{is}$ designed using acrylic to support and combine all line follower robot modules. The design of line follower robots is portable so that each module can be installed and removed easily.
\end{abstract}

KEYWORDS: Electronic Waste Stacking, Portable Robot Design, Line Follower, Robot Design

\begin{abstract}
ABSTRAK: Penumpukan sampah elektronik mulai menjadi sorotan di seluruh dunia. Terlepas dari masalah tersebut kegiatan robotika semakin berkembang di seluruh dunia. Banyak kompetisi robotika yang diadakan sebagai wadah kreatifitas suatu komunitas sehingga mau tidak mau pemanfaatan komponen elektronika pun semakin meningkat. Pemanfaatan komponen elektronika dapat menjadi pemicu penumpukan sampah elektronik. Hal ini tidak dapat terhindarkan karena dalam proses pengembangan robot tidak jarang mengakibatkan modul elektronik yang digunakan mengalami kendala sehingga harus mengganti dengan modul elektronik yang baru. Untuk meminimalisasi penumpukan sampah elektronik dapat dilakukan dengan pembuatan modul elektronik yang portable sehingga beberapa komponen dapat dipasang dan dilepas dengan mudah. Portabilitas modul elektronik yang baik dapat meminimalisasi penggantian komponen jika terjadi kerusakan pada modul. Dalam penelitian ini dibahas tentang rancang bangun robot line follower yang dapat dirangkai secara portable yang didalamnya terdapat beberapa modul yang dapat dipasang dan dilepas dengan mudah. Sensor yang dipakai pada robot ini adalah photodiode, dengan melibatkan kontroler Arduino Nano sebagai pusat kendali, driver motor L298N sebagai driver motor, serta motor DC $12 \mathrm{~V}$ sebagai aktuator. Tidak lupa juga body robot dirancang menggunakan akrilik untuk menopang dan menggabungkan seluruh modul robot line follower. Rancang bangun robot line follower secara portable berhasil direalisasikan sehingga masing - masing modul dapat dipasang dan dilepas dengan mudah.
\end{abstract}

KATA KUNCI: Penumpukan sampah elektronik, desain robot portable, line follower, rancang bangun robot

\section{PENDAHULUAN}

$\mathrm{S}$ ampah elektronik menjadi masalah serius bagi seluruh negara di dunia. Setiap tahun pertumbuhan sampah elektronik mencapai 5\% [1]. Termasuk dalam kategori penyumbang sampah elektronik terbesar, pertumbuhan sampah elektronik di Asia telah mencapai $63 \%$ dalam lima tahun. Salah satu penyebab penumpukan sampah elektronik adalah kualitas komponen yang tidak jarang mengalami kerusakan.

Komponen pada board PCB yang mudah rusak merupakan permasalahan yang kerap terjadi di dunia elektronik. Salah satu contoh komponen yang sering rusak adalah central lock pada mobil. Kerusakan komponen pada central lock tidak dapat diprediksi. Kerusakan bisa saja terjadi pada motor doorlock, switch doorlock, remote, modul, junction block, ataupun jaringan kabel pada central lock [2]. Jadi jika terjadi kerusakan pada central lock, bisa jadi semua komponen harus diganti, meskipun terdapat komponen yang masih bekerja dengan baik

Terlepas dari penggunaan komponen elektronik sehari - hari, di era modern ini tidak sedikit negara yang mengadakan kompetisi robotika bahkan dari tingkat dasar hingga pendidikan tingi. Kontes robot dapat mendorong inovasi dan kreativitas mahasiswa [3]. Meskipun demikian, kompetisi robotika yang marak diadakan ini dapat menjadi salah satu pemicu prosentase penggunaan komponen elektronik yang semakin tinggi.

Penggantian seluruh komponen elektronik pada suatu alat dapat menjadi salah satu penyebab penumpukan sampah elektronik. Tidak kalah penting dari central lock, beberapa komponen pada robot seperti mikrokontroler dapat juga sering mengalami kerusakan. Kerusakan dapat dikarenakan oleh arus berlebih yang masuk mikrokontroler, debu, korsleting jalur pada PCB dan masih banyak penyebab kerusakan lain yang mempengaruhi kinerja mikrokontroler. Lebih parah lagi, jika mikrokontroler berada pada satu papan PCB dengan komponen lain dan mengalami kerusakan, maka satu papan PCB harus diganti beserta komponen lain yang mungkin tidak mengalami kerusakan. Untuk menanggulangi pembuangan limbah elektronik, diperlukan

${ }^{1}$ Program Studi Teknik Elektro Universitas Katolik Indonesia Atma Jaya 
papan komponen/modul pada robot yang mendukung penggantian komponen seperti mikrokontroler dengan mudah sehingga dapat meminimalisir limbah elektronik. Berdasarkan latar belakang masalah yang ada, penelitian ini dibatasi oleh rancang bangun robot portable sehingga pemasangan dan pelepasan komponen elektronik dapat dilakukan dengan mudah. Dalam penelitian ini rancang bangun robot difokuskan pada robot line follower.

\section{ROBOT LINE FOLLOWER}

Robot Line Follower merupakan salah satu jenis robot yang dapat bergerak mengikuti garis. Robot line follower dapat mengikuti jalur yang berupa garis hitam pada papan berwarna putih maupun garis putih pada papan berwarna hitam [4]. Pada dasarnya cara kerja robot line follower adalah dengan menangkap bias cahaya yang dipantulkan pada papan menggunakan sensor. Setelah beda bias cahaya didapat dari sensor, selanjutnya hasil sensor dikirim ke rangkaian ADC (Analog to Digital Converter) yang dalam penelitian ini rangkaian ADC sudah menjadi 1 di dalam mikrokontroler. Data sensor yang sudah melalui ADC diproses dalam mikrokontroler dan selanjutnya diperoleh data keluaran untuk mengendalikan motor melalui driver motor.

\section{RANCANG BANGUN ROBOT}

Robot line follower pada penelitian ini dirancang dalam beberapa bagian modul elektronik pendukung sinyal masukan dan sinyal keluaran sebagai berikut:

1. Modul sensor

2. Modul kontrol

3. Modul driver motor

4. Body robot

5. Aktuator

Rancangan blok diagram robot line follower dapat dilihat pada Gambar 1

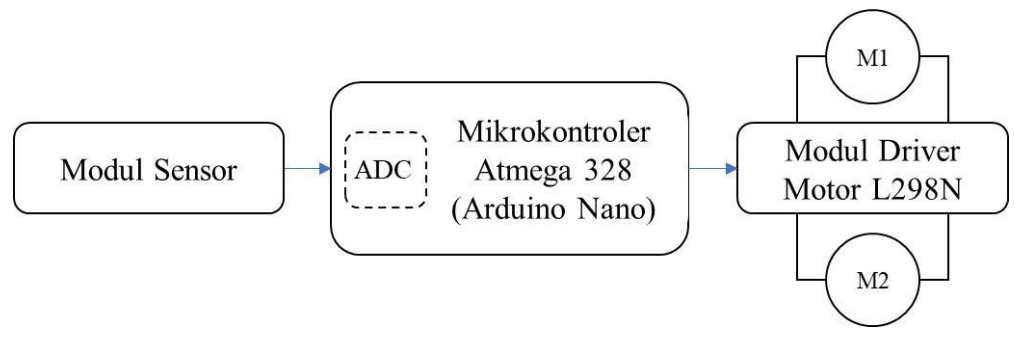

Gambar 1. Blok diagram robot line follower

Sensor yang digunakan dalam modul sensor adalah sensor photodiode. Photodiode merupakan salah satu sensor yang resistansinya dapat berubah saat terkena sinar / cahaya yang didapat dari pancaran LED sebagai transmitter. Nilai resistansi pada photodiode akan semakin besar saat photodiode tidak terkena cahaya, sebaliknya nilai resistansi pada photodiode akan semakin kecil jika photodiode terkena cahaya yang semakin terang. Ilustrasi mengenai kerja sensor photodiode dapat dilihat pada Gambar

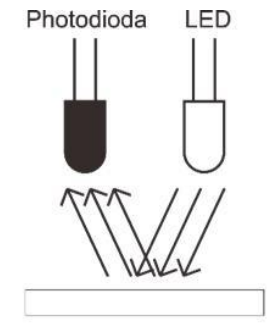

Penampang Garis Putih

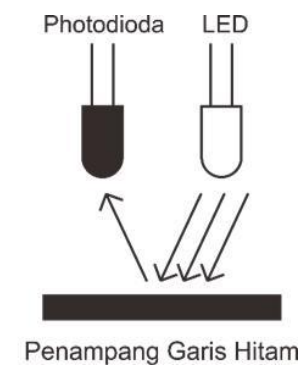

Penampang Garis Hitam

Gambar 2. Ilustrasi kerja sensor photodiode

Pada modul sensor photodiode, data sensor yang didapat masih berupa sinyal analog dan harus dikonversikan ke dalam sinyal digital agar dapat diproses oleh mikrokontroler [5]. Digunakan 8 sensor array photodiode dalam perancangan robot ini. Desain skematik dan desain PCB untuk modul sensor dapat dilihat pada Gambar 3 dan Gambar 4. 


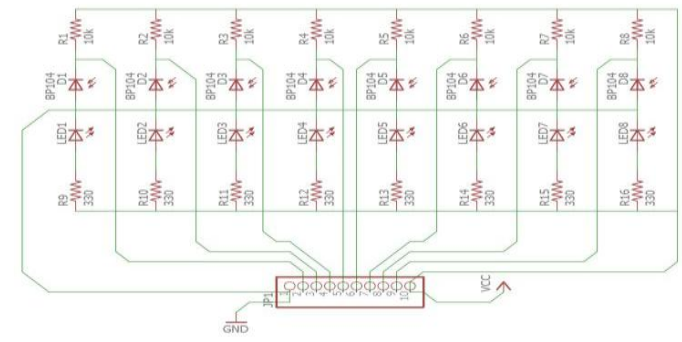

Gambar 3. Desain skematik modul sensor

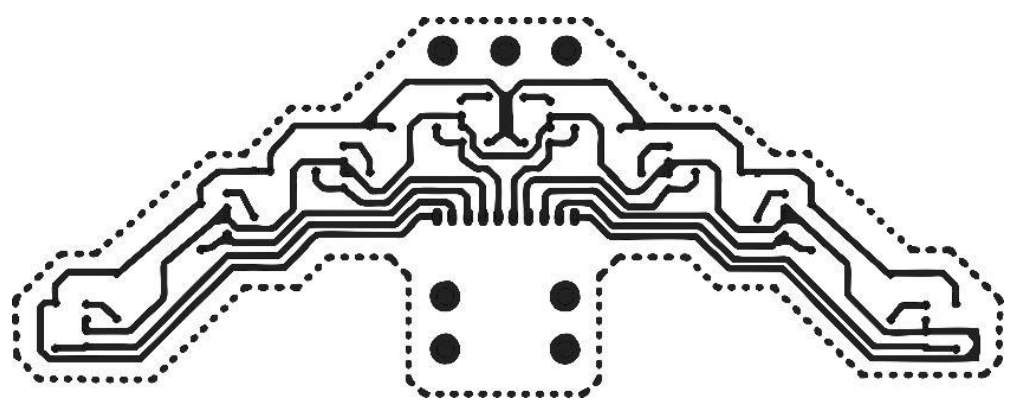

Gambar 4. Desain PCB untuk modul sensor

Sensor didesain agar tidak melebihi ketinggian $5 \mathrm{~mm}$ dari permukaan jalur. Sensor bekerja dengan baik jika terlindung dari gangguan cahaya yang lain karena akan mempengaruhi bias cahaya yang didapat sensor satu dengan sensor lain [6]. Hasil rancangan sensor dapat dilihat pada Gambar 5

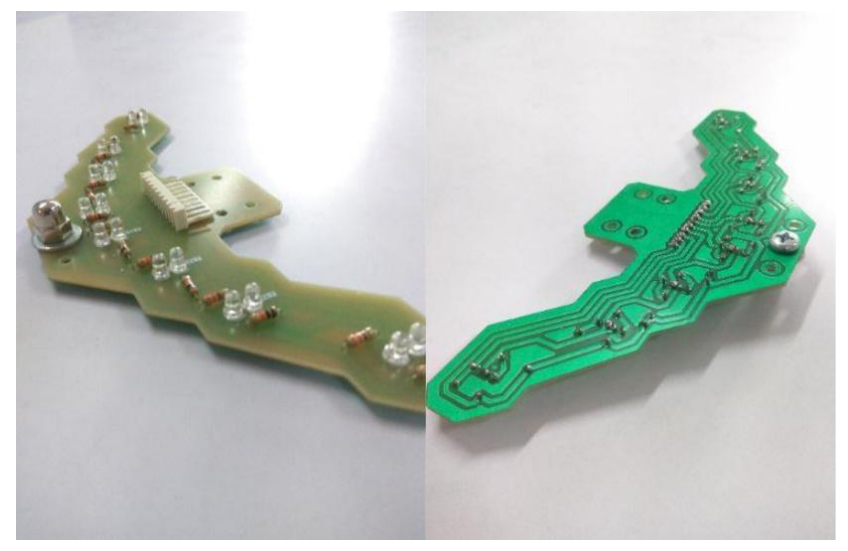

Gambar 5. Hasil rancangan modul sensor garis

Selanjutnya, perangkat yang digunakan sebagai kontroler dalam penelitian ini adalah mikrokontroler Arduino Nano. Arduino Nano merupakan salah satu sistem mokrokontroler berbasis ATmega 328P sebagai pusat kontrolnya. ATmega 328P mempunyai 14 pin input/output digital yang 6 diantaranya dapat digunakan untuk Pulse Width Modulation (PWM), lalu terdapat juga 6 pin input analog, $16 \mathrm{MHz}$ crystal, ICSP, tombol reset, serta koneksi mini USB [7].

Secara spesifikasi Arduino Nano hampir sama dengan Arduino Uno R3 yang juga menggunakan ATmega 328P sebagai pusat kontrolnya. Perbedaan diantara kedua papan mikrokontroler ini terletak hanya pada bentuk papan, ukuran papan, port USB yang digunakan, serta tidak adanya socket untuk power supply pada Arduino Nano. Kelebihan dari penggunaan Arduino Nano adalah perangkat ini mempunyai ukuran yang kecil dan compact.

Kelebihan Arduino Nano yang mempunyai ukuran kecil inilah yang dapat membuat robot terkesan lebih ramping. Perbandingan ukuran Arduino Nano dan Arduino Uno R3 dapat dilihat pada Gambar 6. 


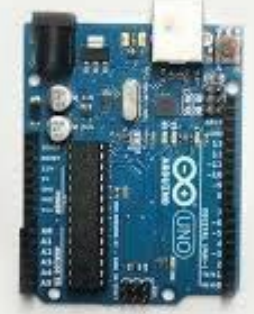

A

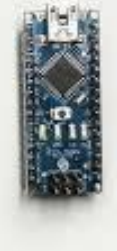

B

Gambar 6. A) Arduino UNO R3; B) Arduino Nano [7]

Seperti Arduino UNO R3, Arduino Nano juga dapat diprogram menggunakan Arduino IDE. Arduino IDE digunakan untuk menuliskan program dan memasukkan program ke dalam Arduino menggunakan kabel USB yang terkoneksi antara komputer dan Arduino. Tampilan dari Arduino IDE dapat dilihat pada Gambar 7.

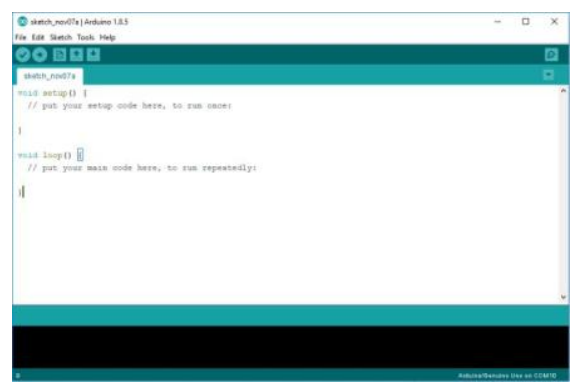

Gambar 7. Arduino IDE

Selain Arduino Nano sebagai kontroler, terdapat beberapa komponen pelengkap yang dapat dipasang dan dilepas secara portable. Penerapan komponen secara portable dimaksudkan agar komponen dapat dengan mudah diganti jika terjadi kerusakan. Komponen yang dapat dipasang secara portable selain mikrokontroler Arduino Nano adalah LCD dan IC shift register. Desain skematik dan desain PCB papan kontroler utama pada penelitian ini dapat dilihat pada Gambar 8 dan Gambar 9.

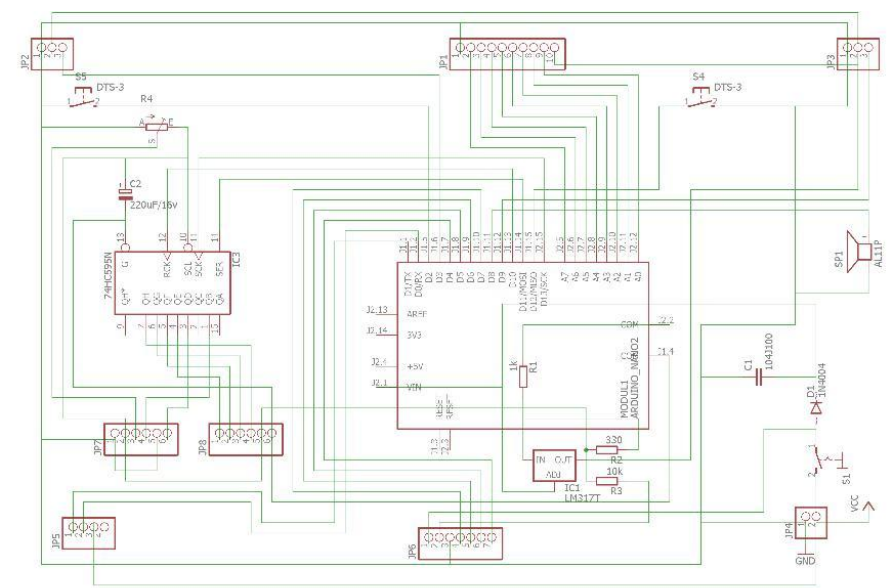

Gambar 8. Desain Skematik Modul Kontrol Utama 


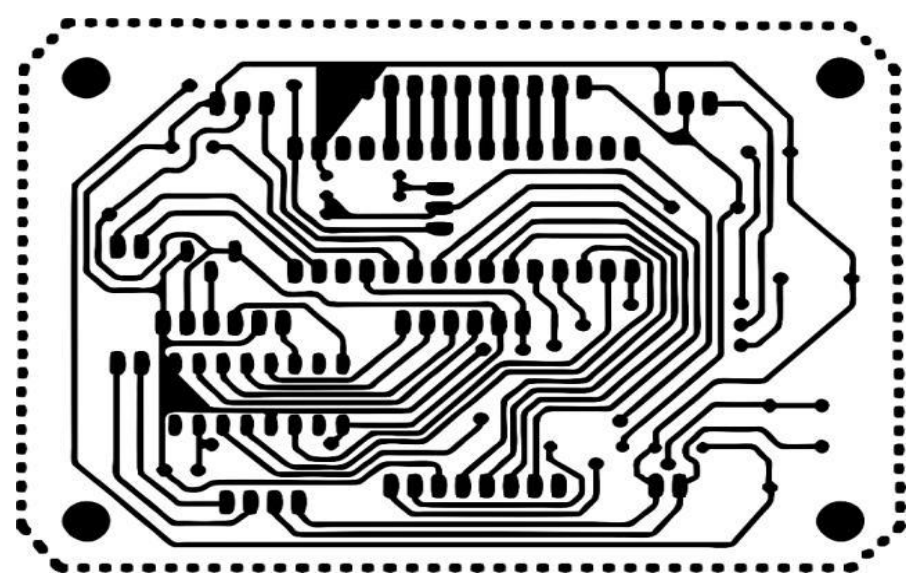

Gambar 9. Desain PCB untuk Modul Kontrol Utama

Perancangan tata letak komponen disesuaikan dengan ukuran Arduino Nano, LCD, dan IC Shift Register agar dapat dengan mudah diganti jika terdapat kerusakan. Papan kontroler utama berhasil dibuat dengan dimensi $10 \mathrm{~cm}$ x $6 \mathrm{~cm}$. Selain itu papan kontroler utama juga didesain agar tidak terlalu banyak kabel yang tidak rapi. Hasil rancangan papan kontroler utama dapat dilihat pada Gambar 10

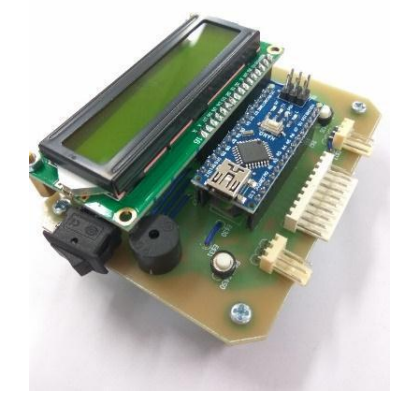

Gambar 10. Hasil papan kontroler utama

Selain modul sensor dan modul kontrol utama, robot line follower memerlukan perangkat pendukung untuk mengendalikan aktuator (motor). Modul driver motor L298N digunakan dalam penelitian ini. Driver motor L29N dirancang untuk mengendalikan dua (2) motor DC dengan dua (2) arah [8]. Modul driver motor L298N dapat dilihat pada Gambar 11.

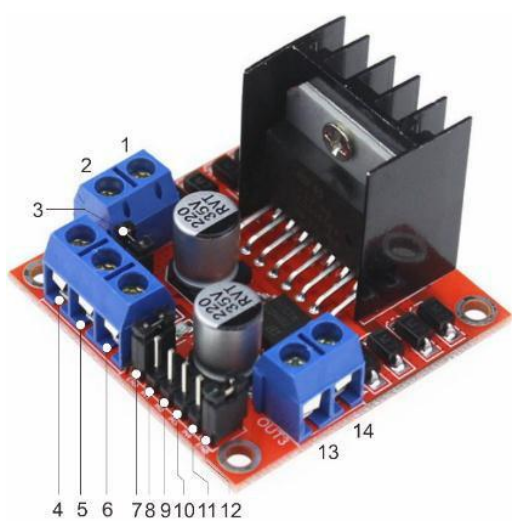

Gambar 11. Modul Driver Motor L298N 
Setiap Pin pada modul driver motor L298N mempunyai fungsi yang berbeda. Berikut adalah keterangan tiap - tiap pin konektor dari modul driver motor L298N:

1. Kutub (+) dari motor DC 1

2. Kutub (-) dari motor DC 1

3. Jumper untuk tegangan suplai $12 \mathrm{~V}$

4. Konektor tegangan masuka

5. Ground

6. Konektor tegangan keluaran $5 \mathrm{~V}$

7. Jumper untuk Motor DC 1

8. Input data 1 dari mikrokontroler

9. Input data 2 dari mikrokontroler

10. Input data 3 dari mikrokontroler

11. Input data 4 dari mikrokontroler

12. Jumper untuk motor DC 2

13. Kutub (+) dari motor DC2

14. Kutub (-) dari motor DC2

Bahan untuk membuat body robot pada penelitian ini menggunakan akrilik dengan ketebalan $3 \mathrm{~mm}$. Body robot didesain agar dapat dengan mudah dan kuat untuk menopang papan - papan komponen robot line follower. Desain body robot dapat dilihat pada Gambar 12

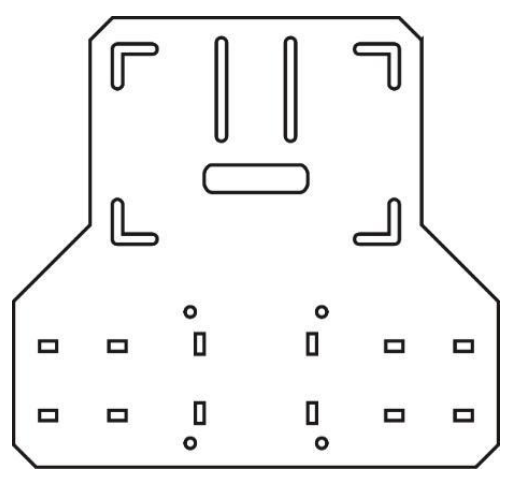

Gambar 12. Desain akrilik untuk body robot

Motor merupakan aspek yang tidak kalah penting pada bagian robot. Motor digunakan sebagai bagian utama pada sistem gerak robot. Kemampuan motor yang digunakan pada robot merupakan faktor krusial pada robot. Hal ini dikarenakan motor mempengaruhi seberapa akurat dan seberapa cepat robot dapat melakukan gerakan untuk menyelesaikan tugas yang dibatasi oleh kondisi spasial dan temporal [9]. Penggerak robot line follower pada penelitian ini didesain menggunakan motor $12 \mathrm{~V}$ yang telah dilengkapi dengan gearbox metal. Motor yang digunakan dalam penelitian ini dapat dilihat pada Gambar 1

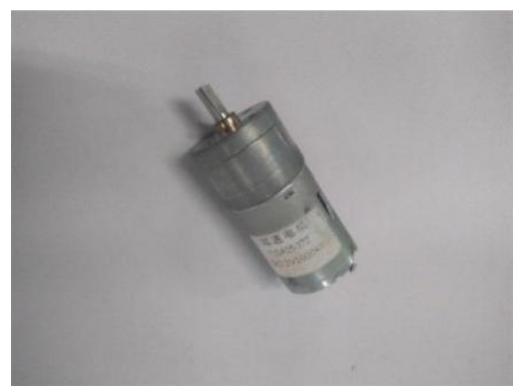

Gambar 13. Motor DC $12 \mathrm{~V}$ dengan gearbox metal 
Selain motor, komponen pendukung gerak robot adalah roda. Roda pada robot terdiri dari ban dan velg. Ban pada roda robot dibuat menggunakan bahan karet, sedangkan velg pada roda dibuat menggunakan 2 lapis akrilik 5mm. Roda pada robot dapat dilihat pada Gambar 14.

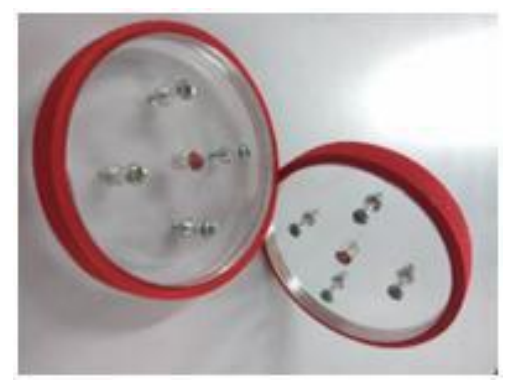

\section{Gambar 14. Roda robot line follower}

Terlepas dari komponen mekanik dan elektrik, robot memerlukan sumber daya untuk mensuplai tegangan ke seluruh rangkaian. Salah satu alternatif sumber daya yang dapat digunakan pada robot adalah baterai. Salah satu baterai yang dapat digunakan pada robot adalah baterai lithium polymer (Li-Po). Baterai Li-Po termasuk jenis baterai yang sering digunakan pada banyak perangkat elektronik. Tidak jarang baterai Li-Po menjadi pilihan bagi konsumen yang memerlukan daya besar dan dalam jangka waktu yang lama [10].

Robot line follower dalam penelitian ini didesain se-portable mungkin sehingga dapat dengan mudah jika terjadi kerusakan pada komponen - komponennya. Perakitan blok komponen adalah sebagai berikut:

1. Pemasangan motor DC dan baterai dengan menggunakan kabel ties. Pemasangan komponen dapat dilihat pada Gambar 15.

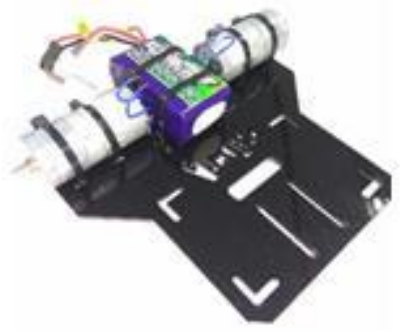

Gambar 15. Pemasangan motor dan baterai pada body robot

2. Pemasangan driver motor di atas baterai. Pemasangan driver motor dapat dilihat pada Gambar 16

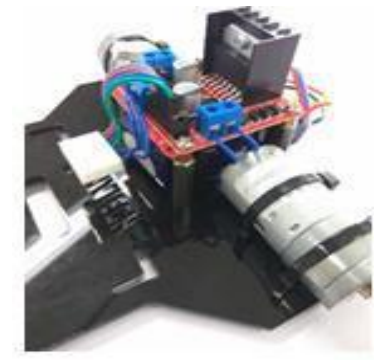

Gambar 16. Pemasangan modul driver motor

3. Pemasangan papan sensor garis di bawah body dengan sensor menghadap ke bawah. Hasil pemasangan papan sensor dapat dilihat pada Gambar 17. 


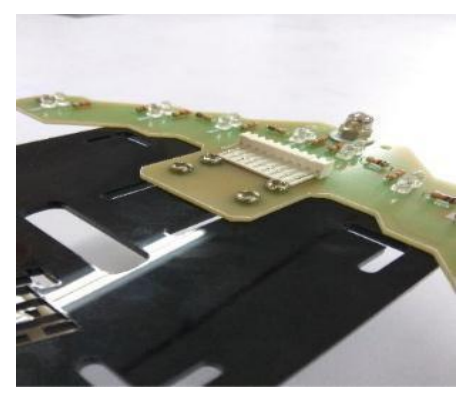

Gambar 17. Pemasangan modul sensor garis pada body robot

4. Pemasangan ujung kabel penghubung pada pin konektor papan sensor. Hasil pemasangan dapat dilihat pada Gambar 18.

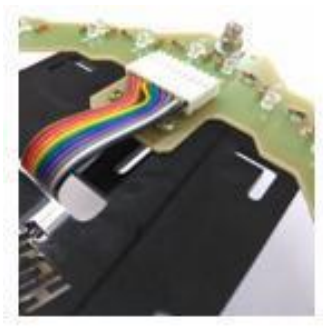

Gambar 18. Pemasangan kabel penghubung pada modul sensor garis

5. Pemasangan ujung lain dari kabel penghubung pada pin konektor modul kontrol utama. Juga dilakukan pemasangan kabel penghubung dari driver motor dan baterai pada pin konektor kontrol utama. Hasil pemasangan dapat dilihat pada Gambar 19.

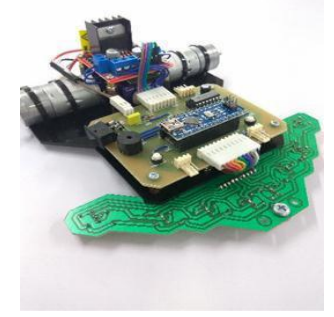

Gambar 19. Pemasangan Kabel Penghubung pada Papan Komponen Utama

6. Pemasangan roda pada motor. Hasil pemasangan dapat dilihat pada Gambar 20.

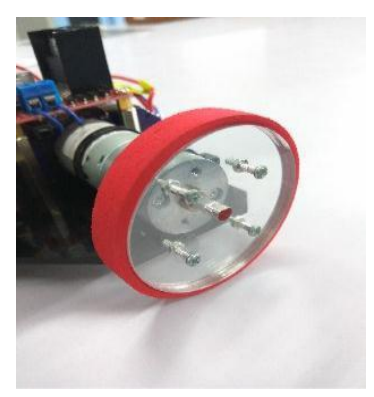

Gambar 20. Pemasangan Roda pada Motor

7. Robot siap untuk diprogram dan dioperasikan. Hasil rancang bangun robot line follower dapat dilihat pada Gambar 21. 


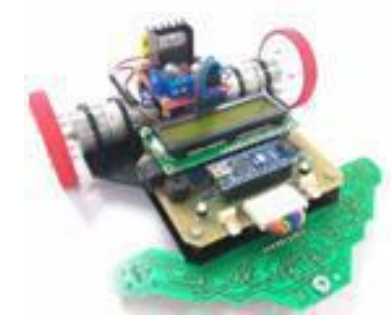

Gambar 21. Hasil rancang bangun robot line follower portable

\section{KESIMPULAN}

Robot line follower pada penelitian ini berhasil dirancang secara portable. Hasil rancang bangun menjadikan robot dalam 5 bagian yaitu: Modul Sensor, Modul Kontrol Utama, Modul Driver Motor L298N, Body Robot, dan Aktuator. Rancangan PCB robot juga dapat meminimalisasi penggunaan kabel jumper yang banyak dan dapat mengakibatkan robot terlihat kurang rapi. Penempatan komponen - komponen penting pada papan kontroler utama juga berhasil diaplikasikan secara portable. Seperti LCD, Arduino Nano, dan IC Shift Register dapat dipasang dan dilepas dengan sangat mudah, sehingga jika terjadi kerusakan pada komponen tersebut dapat segera diganti dengan mudah dan tidak perlu mengganti seluruh komponen pada papan, hal ini dapat mendukung upaya dalam minimalisasi penumpukan sampah elektronik. Penelitian ini tidak berakhir sampai disini, karena diperlukan pengujian pada setiap aspek pendukung robot, baik pada Modul Sensor, Modul Kontrol Utama, kekuatan Body Robot, dan fleksibilitas Aktuator Robot

\section{DAFTAR PUSTAKA}

[1]. Muhammad I. R., 2018, Sampah Elektronik tembus 49,8 Juta Ton. 2017. Internet: https://inet.detik.com/cyberlife/d-3741297/2018-sampah-elektronik-tembus-498-juta-ton. [6 Nov 2018]

[2]. Iwan, A. Ini Komponen Central Lock yang kerap Rusak. 2015. Internet: https://sains.kompas.com/read/2015/11/17/074400730/Ini.Komponen.Central.Lock.yang. Kerap.Rusak . [6 Nov 2018]

[3]. Ainun, N. Seru! Ratusan Robot Buatan Mahasiswa Indonesia Bersaing di Yogya. 2015. Internet:https://news.detik.com/berita-jawa-tengah/d-2941444/seru-ratusan-robot-buatan-mahasiswaindonesia-bersaing-di-yogya . [6 Nov 2018]

[4]. Mehran P., M. Mehdi S., Mahdi R. G.. A Line Follower Robot from design to Implementation: Technical issues and problems. The 2nd International Conference on Computer and Automation Engineering (ICCAE). 2010.

[5]. Cao Quoc Huy, "Line Follower Robot", University UPG din Ploiesti.

[6]. Abhijit P., et al. Line Follower Robot for Industrial Manufacturing Process. International Journal of Engineering Inventions Vol. 6 Issue 10. 2017.

[7]. Store Arduino. "Arduino Nano", 2018. Internet: https://store.arduino.cc/usa/arduino-nano [ 7 Nov 2018 ]

[8]. Dickson N. T. H, et al. Modular Motor Driver with Torque Control for Gripping Mechanism. International Symposium on Robotics and Intelligent Sensors. Procedia Engineering. 2012.

[9]. Hsien-I Lin, C. S. George Lee. Measurement of the Robot Motor Capability of a Robot Motor System: A Fitts's-Law-Inspired Approach. Open Access Journal, sensors. MDPI. 2013.

[10]. Novanky, Rezadita. Sistem Alat Pengisian Baterai Lithium - Polymer Menggunakan Pengontrol CN3063. UGM Yogyakarta. 2014. 